\title{
The stress field of Vrancea region from fault plane solution (FPS)
}

\author{
L. Telesca ${ }^{1}$, V. Alcaz ${ }^{2}$, and I. Sandu ${ }^{2}$ \\ ${ }^{1}$ Consiglio Nazionale delle Ricerche, Istituto di Metodologie per l'Analisi Ambientale, C. da S. Loja, 85050 Tito (PZ), Italy \\ ${ }^{2}$ Moldavian Academy of Sciences, Institute of Geology and Seismology, Academiei str. 3, Chisinau, Moldova
}

Received: 7 June 2011 - Revised: 29 July 2011 - Accepted: 30 August 2011 - Published: 24 October 2011

\begin{abstract}
The fault plane solutions (FPS) of 247 seismic events were used for stress field investigation of the region. The eigenvectors $\boldsymbol{t}, \boldsymbol{p}, \boldsymbol{b}$, and moment tensor $\mathbf{M}$ components for each FPS were defined and computed numerically. The obtained results confirm the hypothesis of subduction-type intermediate depth earthquakes for the Vrancea seismic region and this may be considered the first approximation of the stress field for the whole of the Vrancea (intermediate depth) region.
\end{abstract}

\section{Introduction}

The Vrancea seismic zone is located in the Southeast of the Carpathian region and is characterized by maximal seismic activity at intermediate depths, with epicenters distributed within the ellipse domain $60 \times 30 \mathrm{~km}^{2}$ rotated by azimuth $\theta \approx 45^{\circ}$ according to the major axis (Radu and Polonic, 1982; Constantinescu and Enescu, 1984) (Fig. 1).

The recent relocation of several hypocenters of seismic events has increased the accuracy of the ellipse domain to $90 \times 20 \mathrm{~km}^{2}$ (Radulian et al., 2007; Hurukawa et al., 2008).

To explain the high seismic activity of this region, different seismotectonic models were developed (Constantinescu et al., 1972; Radu, 1974; Constantinescu and Enescu, 1984; Oncescu, 1984; Enescu and Enescu, 1992; Linzer, 1996; Sperner, 1996; Matenco et al., 1997; Enescu and Enescu, 1998; Wortel and Spakman, 2000; Gvirtzman, 2002), but all of them are not in full accordance with the observational data (Bala, 2000). Due to the complexity of the problem, the interpretation of deep Carpathian geo-tectonic processes is still an open scientific debate. At the moment, more often, the dynamic variance of Carpathian seismotectonic model
(Constantinescu and Enescu, 1984) is used, which shows a time-evolution from active to relict subduction. Here, the Carpathians genesis is related to the hypothetical Tethys oceanic plate consumption (Dewey et al., 1973), and its detachment from the continent-continent contact region of tectonic plates (Matenco et al., 1997).

The subject of this investigation is the regional seismic stress field. It has been described earlier (Oncescu, 1987) based on a relatively small amount of crustal and subcrustal fault plane solutions (FPS). Later, for the whole Romanian territory, an analysis of crustal stress field has been done through the zoning procedure of the investigated regions, based on a limited dataset of FPS (Radulian et al., 1996). In the present paper, we used a statistical method and the high density dataset of FPS (for the Vrancea intermediate depth foci zone), to confirm or to correct the previous statements on regional subduction. The statistical method has been applied for the FPS parameters: $\boldsymbol{p}, \boldsymbol{b}, \boldsymbol{t}$.

\section{Data and methodology}

To estimate the Vrancea region stress field, a statistical analysis of the fault plane solutions FPS dataset was performed. This method requires the high dense and omogeneous dataset of FPS for the investigated region. All the FPS data from the available regional catalogues, starting from 1967 up to 2006, has been merged into one unique database (Sandu and Zaicenco, 2008) and used in this study.

According to the concept for shallow depth and intermediate depth events (Radu et al., 1982; Radulian et al., 1996), we divided our dataset into two parts, with $18 \%(\mathrm{~h}<60 \mathrm{~km})$ and $82 \%(60<\mathrm{h}<200 \mathrm{~km})$ from the total number of events, respectively.

\section{Correspondence to: L. Telesca}

(luciano.telesca@imaa.cnr.it)

Published by Copernicus Publications on behalf of the European Geosciences Union. 


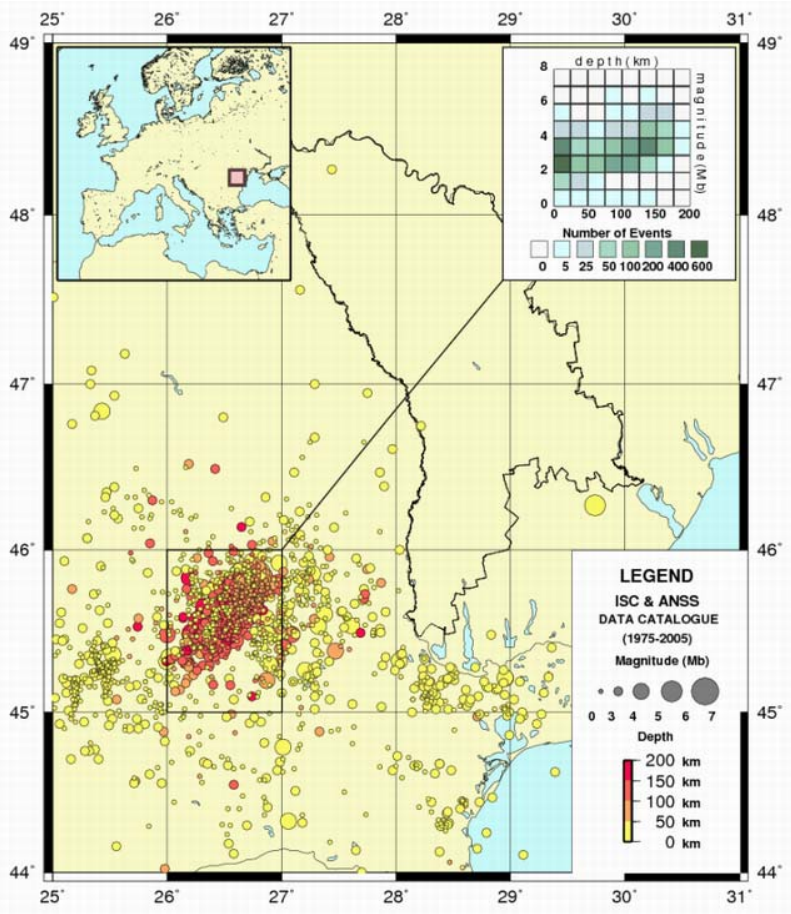

Fig. 1. Vrancea zone.
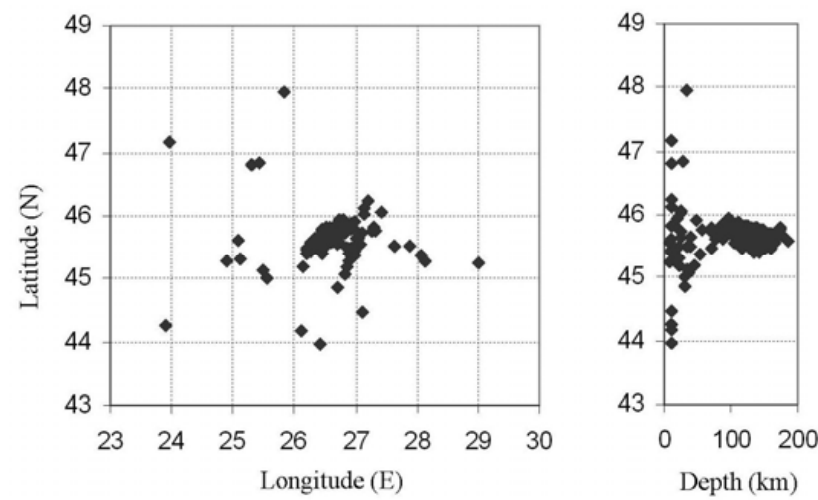

Fig. 2. The hypocenter distribution of selected events.

The very concentrated spatial distribution of the earthquake epicenters in the area (Fig. 2) makes the algorithm of numerical computation of the stress field quite simple; as a result, it becomes easier to select the more appropriate coordinate system for each subgroup of intermediate events (Gephart and Forsyth, 1984). This allows us to undestand how the mechanic stress field changes according to the event depth for the investigated region. We can not say the same for crustal events, which are spread on a much larger area, and according to (Radulian et al., 2002) are characterized by random orientation of the principal stress axes and nodal planes of FPS.

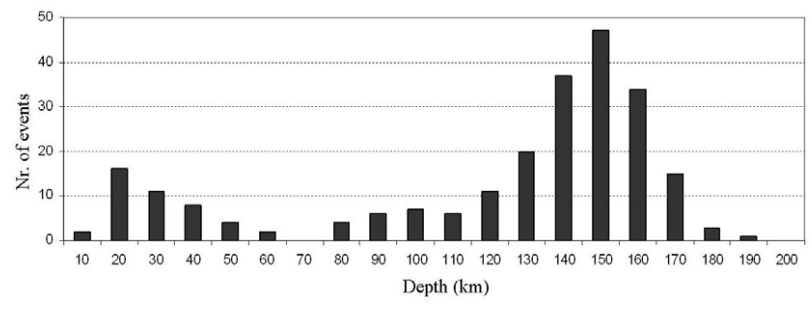

Fig. 3. Depth distributions for the Vrancea region dataset events (Sandu and Zaicenco, 2008).

The highly dense dataset allows us to construct a high resolution image of the stress field, also to obtain a stable FPS due to a large number of intermediate depth events on the investigated region. Therefore, we focused only on the in termediate earthquake dataset (202 events) to define the regional seismic stress field.

From the theory, a fault plane it is completely specified by two angles: the fault strike $\phi$ defined as the azimuth of the strike direction and the dip $\delta$ defined as the angle between a horizontal plane and the fault plane (Koyama, 1997). With respect to a reference system in which the $x$-axis points north, the $y$-axis points east, and the $z$-axis points upwards (Fig. 4), the outward normal $\boldsymbol{n}$ to the fault plane is described by its three components:

$n_{x}=-\sin (\delta) \sin (\phi), n_{y}=\sin (\delta) \cos (\phi), n_{z}=-\cos (\delta)$

The direction of a slip on a fault plane is conveniently described by the rake, which is the angle $\lambda$ between the slip and strike directions. The unit slip vector $s$ is then given as:

$s_{x}=\sin (\lambda) \cos (\delta) \sin (\phi)+\cos (\lambda) \cos (\phi)$,

$s_{y}=-\sin (\lambda) \cos (\delta) \cos (\phi)+\cos (\lambda) \sin (\phi)$,

$s_{z}=-\sin (\lambda) \sin (\delta)$

The tension axis $\boldsymbol{t}$, pressure axis $\boldsymbol{p}$, null axis $\boldsymbol{b}$, can be easily defined through $\boldsymbol{n}, \boldsymbol{s}$ vectors:

$\boldsymbol{t}=\frac{1}{\sqrt{2}}(\boldsymbol{n}+\boldsymbol{s}), \boldsymbol{b}=\boldsymbol{n} \times \boldsymbol{s}, \boldsymbol{p}=\frac{1}{\sqrt{2}}(\boldsymbol{n}-\boldsymbol{s})$

The $\boldsymbol{t}, \boldsymbol{p}, \boldsymbol{b}$ vectors are the eigenvectors of moment tensor M (Lay and Wallace, 1995), which for nontrivial solutions satisfy the condition (secular equation):

$\mathbf{M} \times \boldsymbol{a}=\boldsymbol{m} \times \boldsymbol{a}, \operatorname{det}(\mathbf{M}-\boldsymbol{m} \mathbf{I})=0$

where $\boldsymbol{m}_{1}, \boldsymbol{m}_{2}, \boldsymbol{m}_{3}$ correspond to the eigenvectors; $\boldsymbol{a}_{1}, \boldsymbol{a}_{2}$, $\boldsymbol{a}_{3}$ define the principal axes of the stress $(\boldsymbol{t}, \boldsymbol{p}, \boldsymbol{b})$ (Shearer, 2009), and $\mathbf{I}$ is the identity matrix. 


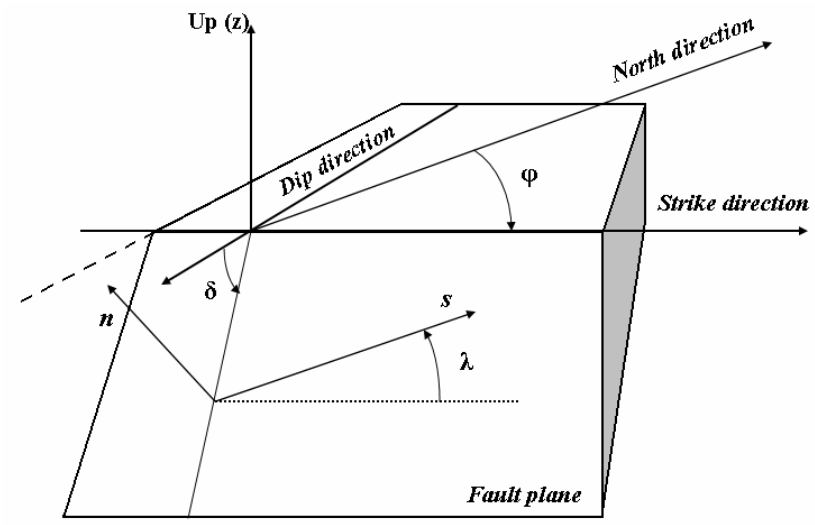

Fig. 4. Geometrical illustration of fault plane, slip direction, the normal direction to the fault plane. The slip vector is the movement of the hanging wall block relative to the footwall block.

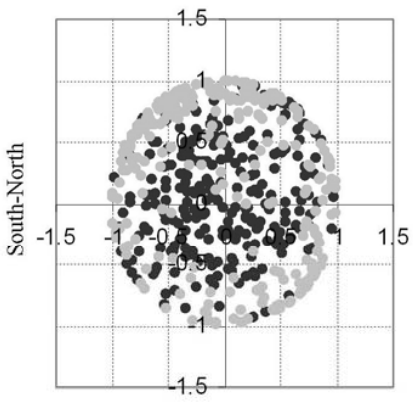

West-East

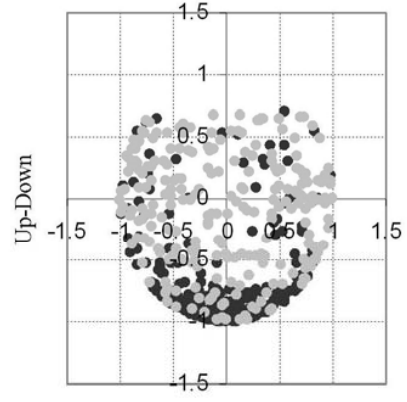

West-East
T axes

Fig. 5. The $\boldsymbol{t}$ and $\boldsymbol{p}$ axes projection for horizontal (left) and vertical (right) profiles.

\section{Results and discussion}

The eigenvectors, which specify the direction of the tension axis $\boldsymbol{t}$, the pressure axis $\boldsymbol{p}$, the null axis $\boldsymbol{b}$, and moment tensor $M$ components for FPS of all 202 intermediate events were computed numerically. Using the vertical components for $\boldsymbol{p}$, $\boldsymbol{t}, \boldsymbol{s}$ (slip) axes, we found that $91 \%$ of the source mechanisms of intermediate depth earthquakes have the same subductiontype features. On the x-z profile, the downward of $t$ axis, and the uniform distribution for both $\boldsymbol{t}, \boldsymbol{p}$ axes in horizontal plane projection are shown clearly, on the $\mathrm{x}-\mathrm{y}$ and $\mathrm{x}-\mathrm{z}$ profiles (Fig. 5). The arguments for supporting the subduction process in the Vrancea region may be the vertical tension axis distribution according to the event's depth. The maximum value for the vertical tension component is more characteristic for intermediate depth, which is represented through the high density plots (Fig. 6). Here, $81 \%$ of the 202 intermediate depth events have the downward slip vector projection distribution (Fig. 6).
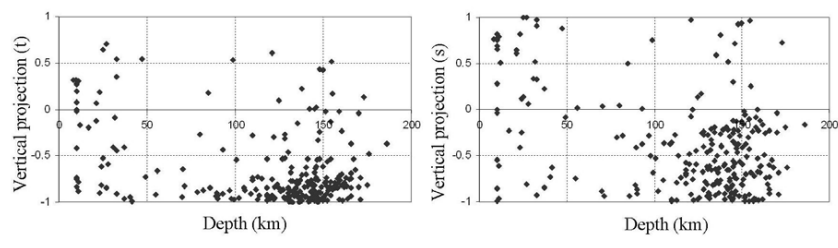

Fig. 6. The tension $(\boldsymbol{t})$ and slip ( $\boldsymbol{s})$ axes distribution profile according to the event depth.

As it is possible to argue, the $\boldsymbol{p}$ and $\boldsymbol{t}$ axes are randomly distributed, showing no preferential stress regime for crustal depths. This behavior has been explained, in the mentioned references, by the existence of a series of active faults in the fractured crust.

At intermediate depths, the stress field is well defined statistically by clear vertical and horizontal orientations for $t, s$ and $\boldsymbol{p}$ axes.

The difference between the crustal and subcrustal stress regime on the Vrancea zone was previously studied (Oncescu and Trifu, 1987) with the stress inversion method applied on a relatively small FPS dataset. We confirmed these results by using a statistical method for a more complete and homogeneous FPS database.

In the context of the obtained results, the following question is relevant: how can the Vrancea intermediate depth subduction process be interpreted in terms of the regional scale tectonics?

Different stress regimes on crustal and subcrustal depth domains give arguments in favor of a break-off plate subduction processes in the region. Hence, the tectonic model, defined by the stress field, can be a partial or complete detached slab of continental crust, evolved into a weak sinking in the upper-part mantle (Oncescu and Trifu, 1987; Wenzel et al., 1999; Radulian et al., 1999, 2004, 2007).

\section{Conclusions}

On the basis of a catalogue of regional earthquakes covering the time interval from 1967 to 2006, a statistical analysis of the seismic stress field characteristics in the Vrancea region was performed. The stress field characteristics were deduced from a fault plane solutions dataset.

A statistical approach requires a highly dense and homogeneous dataset for the investigated region and only intermediate Vrancea events comply with this requirement.

For the Vrancea intermediate depth region, it was found that the slip axis and tension axis have a preferential downward orientation. The compressive axis shows the preferential tectonic cumulative stress. The horizontal cumulative stress and vertical (downward) stress release correspond to the subduction source mechanism (reverse faulting). Statistical analysis shows that almost all (about $91 \%$ ) of the source 
mechanisms of Vrancea intermediate depth earthquakes have the same subduction-type features.

The regional seismic stress field is the main factor for the moment, and this can contribute to a better understanding of the inner processes of the seismogenic zone. Our results support the hypothesis of the existence of a break-off plate subduction process at intermediate depths for the SE Carpathian region.

Acknowledgements. The present study was supported by the CNR/ASM 2011-2012 Project "Characterization of seismicity of Moldova Republic territory. Contribution to seismic hazard assessment". One of the authors (I. Sandu) expresses his sincere gratitude to ICTP for awarding him the STEP fellowship.

Edited by: M. E. Contadakis

Reviewed by: I. Paskaleva and another anonymous referee

\section{References}

Bala, A.: Contributions to the knowledge of structure and dynamics of the lithosphere. Applications in some areas of Romania, $\mathrm{PhD}$ thesis, Bucharest, Institute of Atomic Physics - NIEP, 2000 (in Romanian).

Constantinescu, L. and Enescu, D.: A tentative approach to possibly explaining the occurrence of the Vrancea earthquakes, Rev. Roum. Geol. Geophys. Geogr. Geophysique, 28, 19-32, 1984.

Constantinescu, L., Cornea, I., and Enescu, D.: Structure de la croute terestre en Roumanie d'apres les donnes geophysiques, Rev. Roum. Geol. Geophys. Geogr. Geophysique, 16, 3-21, 1972.

Dewey, J. F., Pitman, W. C., Ryan, W. B. F., and Bonnin, J.: Plate Tectonics and the evolution of the Alpine system, Geol. Soc. of America Bull., 84, 3137-3180, 1973.

Enescu, D. and Enescu, B. D.: On the subduction process in the zone presently occupied by the Carpathians, Revue Romaine de Physique, 37, 525-533, 1992.

Enescu, D. and Enescu, B. D.: Seismotectonic model regarding the genesis and the occurrence of Vrancea (Romania) earthquakes, Rom. Rep. Phys., 50, 97-122, 1998.

Gephart, J. W. and Forsyth, D. W.: An improved method for determining the regional stress tensor using earthquake focal mechanism data: Application to the San Fernando Earthquake sequence, J. Geophys. Res., 89, 9305-9320, 1984.

Gvirtzman, Z.: Partial detachment of a lithospheric root under the Southeast Carpathians: Toward a better definition of the detachment concept, Geology, 30, 51-54, 2002.

Hurukawa, N., Popa, M., and Radulian, M.: Relocation of large intermediate-depth earthquakes in Vrancea region, Romania, since 1934 and a seismic gap, Earth Planets Space, 60, 565-572, 2008.

Koyama, J.: The Complex Faulting Process of Earthquakes (Modern Aproaches in Geophysics), Springer-Verlag, New York, 208 pp., 1997.
Lay, T. and Wallance, T.: Seismic sources, Modern Global Seismology, Academic Press, 1995.

Linzer, H.-G.: Kinematics of retreating subduction along the Carpathian arc, Romania, Geology, 24, 167-170, 1996.

Matenco, L., Zoetemeijer, S., Cloetingh, S., and Dinu, C.: Lateral variations in mechanical properties of the Romanian external Carpathians, 1997.

Oncescu, M. C.: Deep structure of Vrancea region, Romania, inferred from simultaneous inversion for hypocenters and 3-D velocity structure, Ann. Geophys., 2, 23-28, 1984, http://www.ann-geophys.net/2/23/1984/.

Oncescu, M. C.: On the stress tensor in Vrancea region, J. Geophys., 62, 62-65, 1987.

Oncescu, M. C. and Trifu C. I.: Depth variation of the moment tensor principal axes in Vrancea (Romania) seismic region, Ann. Geophys., 5B, 149-154, 1987.

Radu, C.: Contribution a l'etude de la seismicite de la Romanie et comparaison avec la seismicite de Bassin Mediterraneen et en particulier avec la seismicite du sud-est de la France, $\mathrm{PhD}$ thesis, Universite de Strasbourg, 1974.

Radu, C. and Polonic, G.: Seismicity Romanian territory with special reference to the region of Vrancea, Romania earthquake in the March 4, 1977, RSR Academy Publishing House, Bucharest, 75-136, 1982.

Radulian, M., Mândrescu, N., Popescu, E., Utale, A., and Panza, G.: Seismic activity and stress field characteristics for the seismogenic zones of Romania, IC/96/256, 1-11, Trieste, Italy, 1996.

Radulian, M., Bala, A., and Popescu, E.: Fault Plane Solution as Indicators of Specific Stress Field Characteristics in Vrancea and Adjiacent Seismogenic Zones, edited by: Lungu, D., Wenzel, F., Mouroux, P., and Tojo, I., Proceedings of International Conference Earthquake Loss Estimation and Risk Reduction, Bucharest, Romania, 151-161, 2004.

Radulian, M., Bonjer, K.-P., Popa, M., and Popescu, E.: Seismicity patterns in SE Carpathians at crustal and subcrustal domains: tectonic and geodynamic implications, Proc. CRC-461 International Symposium on Strong Vrancea Earthquakes and Risk Mitigation, MATRIX ROM, Bucharest, 93-102, 2007.

Sandu, I. and Zaicenco, A.: Focal mechanism solutions for Vrancea seismic area, in: Harmonization of Seismic Hazard in Vrancea Zone, Springer, 17-46, 2008.

Shearer, P. M.: Introduction to Seismology, Cambridge Univ. Press, 17-38, 2009.

Sperner, B.: Computer programs for the Kinematic analysis of brittle deformation structures and the Tertiary tectonic evolution of the Western Carpathians. Tubinger Geowiss, Arbeiten, A27, 120 pp., 1996.

Wenzel, F., Lorentz, F. P., Sperner, B., and Oncescu, M. C.: Seismotectonics of the Romanian Vrancea Area, in: Vrancea Earth, Tectonics, Hazard and Risk Mitigation, Ser. Advances in Nat. and Technol. Hazards Research, The Netherlands, Editorial Office Kluer Acad. Publish., 15-25, 1999.

Wortel, M. J. R. and Spakman, W.: Subduction and slab detachment in the Mediterranean - Carpathian region, Science, 290, 1910$1917,2000$. 